\title{
Involvement of hyaluronan synthesis in ovarian follicle growth in rats
}

\author{
Noriyuki Takahashi ${ }^{1}$, Wataru Tarumi ${ }^{1}$ and Bunpei Ishizuka ${ }^{2}$ \\ ${ }^{1}$ Department of Obstetrics and Gynecology and ${ }^{2}$ Advanced Reproductive Medicine, St Marianna University School of \\ Medicine, Sugao 2-16-1, Miyamae-ku, Kawasaki, Kanagawa 216-8511, Japan \\ Correspondence should be addressed to N Takahashi; Email: n-tkhs@marianna-u.ac.jp
}

\begin{abstract}
Most of the previous studies on ovarian hyaluronan (HA) have focused on mature antral follicles or corpora lutea, but scarcely on small preantral follicles. Moreover, the origin of follicular HA is unknown. To clarify the localization of HA and its synthases in small growing follicles, involvement of HA in follicle growth, and gonadotropin regulation of HA synthase (Has) gene expression, in this study, perinatal, immature, and adult ovaries of Wistar-Imamichi rats were examined histologically and biochemically and by in vitro follicle culture. HA was detected in the extracellular matrix of granulosa and theca cell layers of primary follicles and more advanced follicles. Ovarian HA accumulation ontogenetically started in the sex cords of perinatal rats, and its primary site shifted to the intrafollicular region of primary follicles within 5 days of birth. The Has1-3 mRNAs were expressed in the ovaries of perinatal, prepubertal, and adult rats, and the expression levels of Has1 and Has2 genes were modulated during the estrous cycle in adult rats and following administration of exogenous gonadotropins in immature acyclic rats. The Has1 and Has2 mRNAs were predominantly localized in the theca and granulosa cell layers of growing follicles respectively. Treatments with chemicals known to reduce ovarian HA synthesis induced follicular atresia. More directly, the addition of Streptomyces hyaluronidase, which specifically degrades HA, induced the arrest of follicle growth in an in vitro culture system. These results indicate that gonadotropin-regulated HA synthesis is involved in normal follicle growth.
\end{abstract}

Reproduction (2014) 147 189-197

\section{Introduction}

The extracellular matrix (ECM) is composed of sulfated and non-sulfated glycosaminoglycans and structural proteins such as collagens and laminins. Hyaluronan (HA) is the only non-sulfated glycosaminoglycan and consists of $\mathrm{N}$-acetylglucosamine and glucuronic acid. $\mathrm{HA}$ is essential for cell migration and proliferation, morphogenesis, wound healing, inflammation, and vascular integrity (Ochsner et al. 2003, Genasetti et al. 2008). High-molecular weight HA accumulates on the cell surface by binding to transmembrane receptors and synthases (HASs) with other hyaladherins (Fries \& Kaczmarczyk 2003), and the HA-rich ECM inhibits angiogenesis (West \& Kumar 1989, Spicer \& Tien 2004). On the other hand, degraded low-molecular weight soluble HA stimulates angiogenesis (Lennon \& Singleton 2011). The production and degradation of HA in vertebrates are regulated by at least three types of HASs and several types of hyaluronidase (HYAL) respectively. The expression of each HAS isoform is spatially and temporally controlled in a unique fashion when mammalian cells are stimulated with cytokines (Itano 2008). The disruption of the Has2 gene causes embryonic lethality due to a defect in the formation of the cardiac jelly matrix, which allows the heart to fold during its development (Camenisch et al. 2000, Itano 2008).

The HA content of ovaries is lower than that of other urogenital organs such as the urinary bladder, uterus, vagina, and penis, and the main sites of $\mathrm{HA}$ accumulation in ovarian follicles are the ECMs of the theca interna, liquor folliculi, and zona pellucida of large antral follicles, but not those of small preantral follicles (Laurent et al. 1995, Irving-Rodgers \& Rodgers 2005). During ovulation, HA accumulation with marked morphological change occurs in the cumulus-oocyte complex; this process is referred to as cumulus expansion. The expansion occurs in cumulus cells of mature preovulatory follicles by a gonadotropin surge that upregulates HAS2 activity via autocrine/paracrine epidermal growth factor signaling (Richards 2005). Cumulus expansion is required for the maintenance of the natural fertilization process by preventing physical damage, dehydration, and polyspermy (Salustri et al. 1999). In assisted reproductive technology, the morphological change has been utilized as a useful indicator of oocyte maturation. After ovulation, HA reduction occurs in the ECM of the remaining mural and membrana granulosa cells of ovulated follicles, i.e. corpora lutea 
(Laurent et al. 1995). Similar HA reduction is observed in the granulosa cell layer of antral follicles under atresia (Salustri et al. 1999, Hatzirodos et al. 2012).

As has been described above, most of the ovarian $\mathrm{HA}$ research has focused on the accumulation in the cumulus cells of preovulatory antral follicles, but not on the production in small growing preantral follicles or the developing ovary, even though ECM constituents other than HA such as collagens, laminin, proteoglycans, and sulfated glycosaminoglycans are localized in small preantral follicles and play roles in folliculogenesis (Irving-Rodgers et al. 2010, Hatzirodos et al. 2012). A histological study carried out by Dumaresq-Doiron et al. (2011) has illustrated HA expression in the growing preantral follicles of WT and Hyal1-knockout mice for the first time. However, the involvement of HA production in folliculogenesis has not been addressed, as the modulation in HA content could not be induced in the ovaries of the Hyal1-deficient mice. Considering the function of $\mathrm{HA}$ along with other ECM components and mechanisms in HA synthesis, it would not be surprising that HA production in the ECMs of immature preantral follicles or developing ovaries is involved in the maintenance of folliculogenesis. It is also important to determine when HA starts to be produced in the ovary and which factor(s) regulate HA synthesis during follicular growth; therefore, in this study, we first examined $\mathrm{HA}$ expression in growing preantral follicles of adult rats and in perinatal developing ovaries of rats. We then investigated the expression and localization of Has genes in small preantral follicles. As a mechanistic insight, gonadotropin regulation of Has gene expression in small follicles was examined using acyclic immature rats, the ovaries of which have fewer antral follicles. Furthermore, the effects of HA reduction on follicle growth were examined in vivo and by in vitro follicle culture, to determine the necessity of $\mathrm{HA}$ for the maintenance of normal follicular growth.

\section{Materials and methods}

\section{Reagents}

All the chemicals were purchased from Sigma Chemical Co. or Wako Pure Chemical Industries (Tokyo, Japan), unless otherwise indicated.

\footnotetext{
Animals

Ovaries obtained from female Wistar-Imamichi rats at various ontogenetic stages were examined (each $n=3-12$ ): untreated rats at embryonic day 19 (E19), rats at postnatal day 1 (P1), P5, and $\mathrm{P} 10$ as perinatal samples, and 10 -week-old adults rats and 100-week-old senescent rats were used for the examination of ovarian HA expression. Ovarian follicles obtained from P14 rats were used for in vitro follicle culture. P21 rats were also used to examine the effects of exogenous gonadotropins and chemicals such as 4-methylumbelliferone (4-MU) and
}

6-diazo-5-oxo-1-norleucine (DON). In this study, $10 \mathrm{IU}$ of equine chorionic gonadotropin (eCG) and human CG (hCG) were used. The minimal pharmacological doses needed to reduce P21 rat ovarian HA synthesis in 2 days were preliminarily determined to be $3.85 \mathrm{~g} / \mathrm{kg}$ body weight for $4-\mathrm{MU}$ by oral administration and $5 \mathrm{mg} / \mathrm{kg}$ for DON by i.p. injection. Some of the 4-MU- or DON-treated rats were simultaneously injected with 10 IU eCG. The stage of estrous cycle was determined in adult rats by vaginal cytology. Ovaries dissected immediately after decapitation of the rats were fixed with $4 \%$ paraformaldehyde overnight for histological studies or stored at $-80{ }^{\circ} \mathrm{C}$ for RT-PCR. All the experimental protocols were approved by the St Marianna University School of Medicine Animal Care and Use Committee.

\section{RT-PCR}

Total RNA $(1 \mu \mathrm{g})$ was extracted and from the ovaries of P10 and P21 rats treated with either none of the chemicals, saline, eCG, or hCG, 10-week-old rats in each estrous cycle, and 100-weekold rats ( $n=4-8$ for each animal group). The extracted total RNA was reverse transcribed to obtain cDNA samples that were used as the templates of routine and real-time PCRs. The sequences of primer sets used for the amplification of the Has and $\beta$-actin genes by routine PCR were Has 1 sense, tggactacgtgcaggtctgt; Has1 antisense, ataggtcatccacgcgtggt; Has2 sense, gagcactgggcagaagcgtg; Has2 antisense, tcctctaaggcagctggcgaaa; Has3 sense, tcagtggactacatccaggt; Has3 antisense, gaccactgactcataggtcatc; $\beta$-actin sense, gacaacggctccggcatgtgca; and $\beta$-actin antisense, tgaggatgcctctcttgctctg. Routine PCR was carried out using an RNA PCR Kit (AMV) ver.3.0 (TaKaRa, Shiga, Japan) with the following conditions: $30 \mathrm{~s}$ of denaturation at $94{ }^{\circ} \mathrm{C}$ followed by annealing and extension at $72{ }^{\circ} \mathrm{C}$ for 30 cycles. The annealing temperatures were $58{ }^{\circ} \mathrm{C}$ for Has $1,63{ }^{\circ} \mathrm{C}$ for Has2 and $\beta$-actin, and $55{ }^{\circ} \mathrm{C}$ for Has3. To quantify the expression levels of Has1 and Has2 genes, real-time PCR was carried out using the ABI 7500 Fast Real-Time PCR System and the TaqMan Gene Expression Master Mix and Assays for rat Has1 (Rn00597231_m1) and Has2 (Rn00565774_m1) (Applied Biosystems), according to the manufacturer's recommendations. The Sequence Detection System software was used for raw data processing and analysis (ver. 1.3.1). The data for each gene as threshold cycle $(C \mathrm{t})$ values were normalized with those for $\beta$-actin (Rn00667869_m1) and with averages of control or initial $\Delta C$ t values and then expressed as $2^{-1 / \Delta \Delta C t}$ values.

\section{Histology}

HA was histochemically detected using the HA-binding protein according to the manufacturer's instructions. Paraffin sections ( $6 \mu \mathrm{m} ; n=4-6$ for each animal group) were rehydrated and incubated with $2 \mu \mathrm{g} / \mathrm{ml}$ biotinylated HA-binding protein (Seikagaku Biobusiness Corp., Tokyo, Japan) at room temperature for $2 \mathrm{~h}$, followed by incubation with peroxidaseconjugated streptavidin for $5 \mathrm{~min}$ (Histofine SAB-PO Kit, Nichirei, Tokyo, Japan). The sections pretreated with 100 TRU Streptomyces HYAL were also prepared as negative controls. Signals were detected by development with 
3,3'-diaminobenzidine, and the sections were counterstained with Mayer's hematoxylin, dehydrated with a graded series of ethanol, and mounted with Entellan (Merck). No signals were detected in sections pretreated with the HYAL. The developmental stages of the follicles were determined as described previously (Pedersen \& Peters 1968). Follicles with condensed nuclei in the granulosa cell layer, poorly developed granulosa cell layer itself, and/or expanded theca cell layer with scarce granulosa cell layer were considered to be atretic.

The localization of Has1 and Has2 mRNAs in the ovary ( $n=3$ for each gene) was examined by fluorescent in situ hybridization, as described elsewhere (Takahashi et al. 2008). The primer sequences used to obtain sense and antisense RNA probes were Has1 sense, taatacgactcactatagggtggggactgagttaccttc; Has1 antisense, aattaacctcactaaagggcctggtcctataatcccact; Has2 sense, taatacgactcactatagggtgtcaatcttctgctgcctc; and Has2 antisense, aattaacctcactaaagggtctccacacagggagagttg.

\section{In vitro follicle culture}

We studied the direct effect of $\mathrm{HA}$ reduction on ovarian follicles in vitro using previously described mouse single-follicle culture techniques (Tarumi et al. 2012). The established culture system is based on previous research carried out by Romero \& Smitz (2009), and oocytes from in vitro-cultured follicles have competence to get matured when treated with hCG/EGF on the 12th day of culture. Growing secondary follicles (100-140 $\mu \mathrm{m}$ in diameter) were isolated from three P14 rats and cultured in $75 \mu \mathrm{l}$ of $\alpha-M E M$ containing $10 \%$ fetal bovine serum, $10 \mu \mathrm{g} / \mathrm{ml}$ insulin, $5.5 \mu \mathrm{g} / \mathrm{ml}$ transferrin, $5 \mathrm{ng} / \mathrm{ml}$ sodium selenite, and $100 \mathrm{mIU} / \mathrm{ml}$ recombinant follicle-stimulating hormone (FSH; Follistim; Merck \& Co., Inc.) in 96-well microplates ( $n=8-10$ per group). In each well, a single follicle was cultured with the following: no treatment; $10 \mathrm{TRU} / \mathrm{ml}$ HYAL from Streptomyces hyalurolyticus, which specifically degrades HA but not the other glycosaminoglycans; or 4-MU $(0.1,0.3$, or $1 \mathrm{mM})$ for 6 days. Half of the culture media $(40 \mu \mathrm{l})$ was changed every other day, and the diameters of the follicles were measured on days 0,3 , and 6 .

\section{Statistical analysis}

All values are expressed as means \pm S.E.M. Differences among the groups at each time point or between different time points were analyzed by a non-parametric ANOVA (Kruskal-Wallis $H$ test) followed by Dunn's post hoc comparison.

\section{Results}

\section{Detection of $\mathrm{HA}$ in adult and perinatal ovaries}

In the ovaries of 10- to 12-week-old (10-week-old) adult rats, HA was detected in the ECMs of theca and granulosa cell layers, including the basal lamina of primary and antral follicles, but it was present only in low amounts in atretic follicles (Fig. 1A, B, C, D and E). During the estrous cycle, there were no changes in the intensities of HA signals in growing follicles. HA was
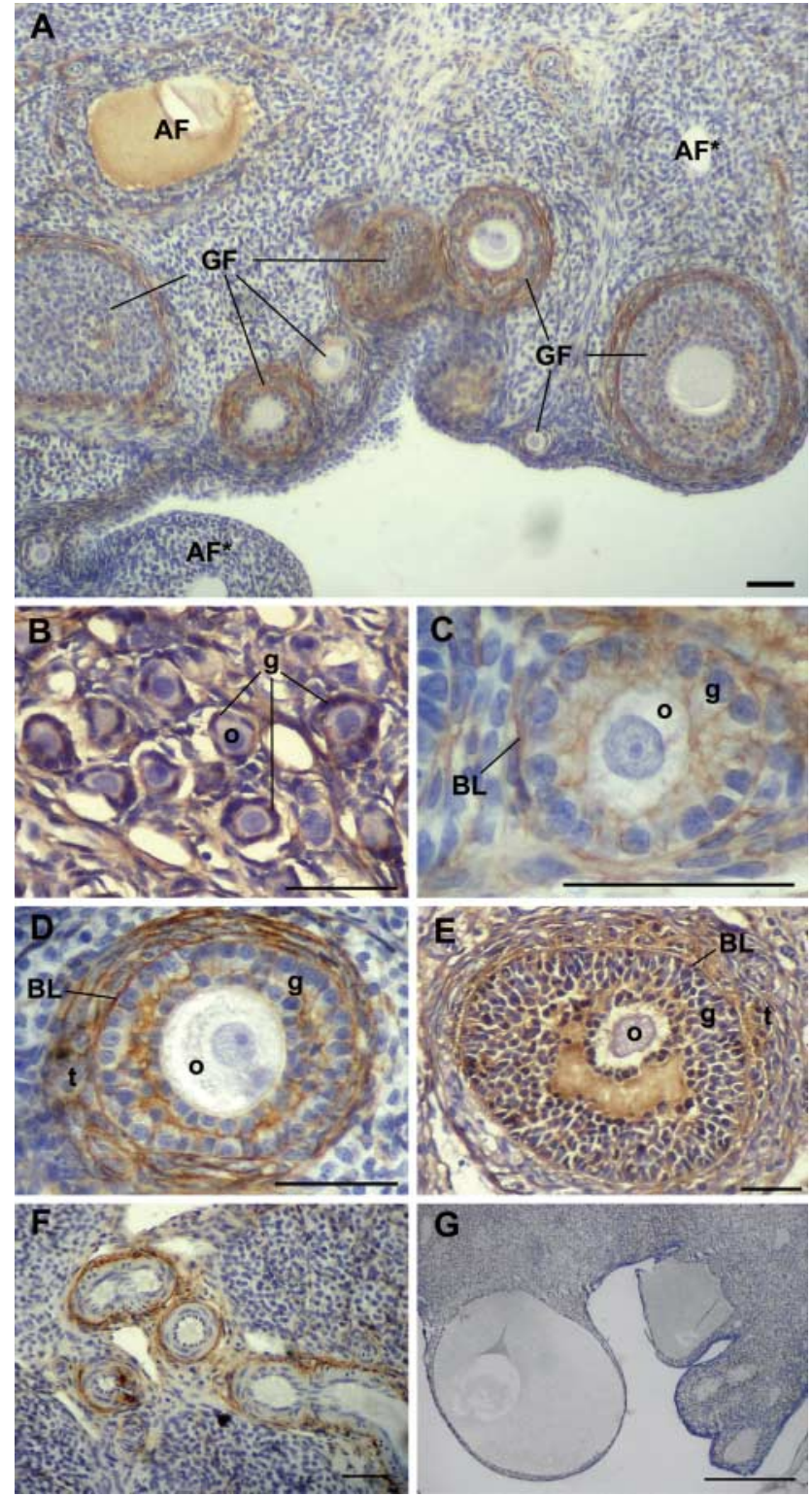

Figure $1 \mathrm{HA}$ localization in the ovaries of adult rats. (A) Lowmagnification view of $\mathrm{HA}$ accumulation. $\mathrm{HA}$ was detected in the ECM of theca and granulosa cell layers of growing preantral follicles (GFs) but not in those of atretic follicles (AFs). AF, AF with poorly developed granulosa cell layer and condensed nuclei; $\mathrm{AF}^{*}, \mathrm{AF}$ with an expanded theca cell layer and scarce granulosa cells. (B, C, D and E) HA in developing follicles. HA was detected in the ECM of the granulosa cell layer of small primary (B), large primary (C), secondary (D), and antral (E) follicles. Basal lamina (BL) of large primary, secondary, and antral follicles and theca layer of secondary (D) and antral (E) follicles were also HA positive. (F) Tunica adventitia of ovarian blood vessels was also HA positive. (G) HA was scarcely detected in the ovaries of 100-weekold rats. $n=4$. Scale bars, $1 \mathrm{~mm}$ for $\mathrm{G}$ and $100 \mu \mathrm{m}$ for others. o, oocyte; $\mathrm{g}$, granulosa cell layer; $\mathrm{t}$, theca cell layer.

also detected in the tunica adventitia of ovarian arteries (Fig. 1F), but was scarcely detected in the interstitial region of ovaries of cycling adult rats (Fig. $1 \mathrm{~A}, \mathrm{~B}, \mathrm{C}, \mathrm{D}, \mathrm{E}$ and $F$ ) and ovaries of 100-week-old senescent rats with 
a large majority of interstitial regions, atretic follicles, and cysts (Fig. 1G). No signals were detected in sections pretreated with the HYAL.

To identify the origin of follicular HA, we used developing ovaries obtained from perinatal rats. HA was found in the sex cords of ovaries of E19 rats (Fig. 2A) and in the interstitial region of ovaries of $\mathrm{P} 1$ rats (Fig. 2B), but not in naked oocytes or primordial follicles. Follicular $\mathrm{HA}$ accumulation began in the granulosa cell layer of primary follicles from P5 (Fig. 2C) and continued to be detected in more mature follicles afterwards (Fig. 2D).

\section{Expression of Has1, Has2, and Has3 in rat ovary during estrous cycle}

In the ovaries of proestrus rats, the Has1 and Has2 genes were intensely expressed and the Has3 gene was expressed at lower levels (Fig. 3A, B and C). The ovarian expression of both Has 1 and Has2 genes was relatively high during ovulation while being low in diestrus and metestrus of cycling adult rats and in acyclic P10 and 100-week-old rats, whereas the mRNA levels of ovarian Has3 were unregulated by the estrous cycle (Fig. 3D and $\mathrm{E})$. The Has1 mRNA was mainly localized in the extrafollicular theca region of preantral (Fig. 3F) and antral (Fig. 3G) follicles, whereas the Has2 mRNA was found in the granulosa cell layer of ovaries of adult rats (Fig. $3 \mathrm{H}$ and $\mathrm{I}$ ).
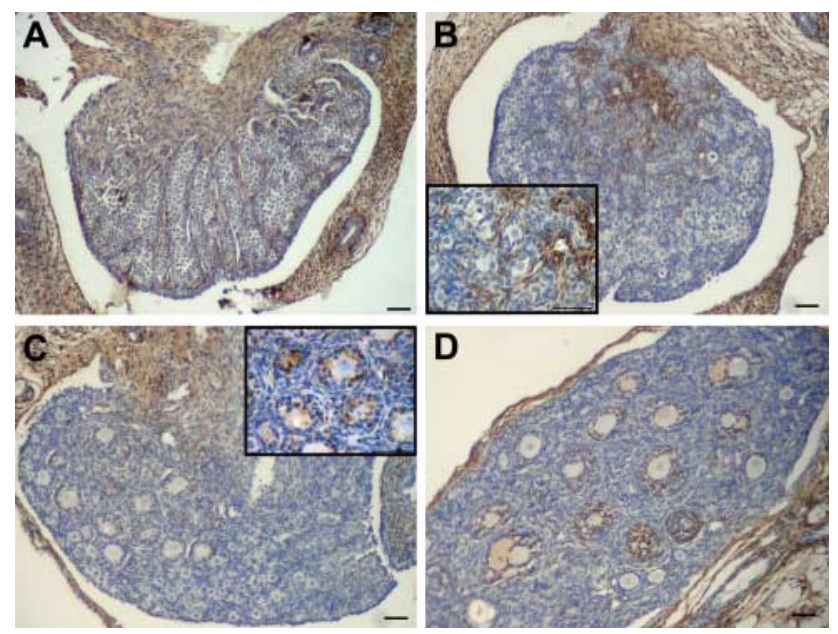

Figure $2 \mathrm{HA}$ localization during ovarian development. (A, B, C and D) HA staining in ovaries obtained from E19 (A), P1 (B), P5 (C), and P10 (D) rats. (A and $B$ ) Interstitial cells with blood vessels intruding into the ovary were prominently $\mathrm{HA}$ positive, whereas no signals were detected in naked oocytes and primordial and primary follicles at E19 and P1. (C) HA was detected in the ECM of granulosa cell layers of primary and secondary follicles at P5. (D) An ovary from P10 rat contained larger growing follicles with more intense HA signals. Magnified views of several images are shown. $n=3-6$ per developmental group. Scale bars, $100 \mu \mathrm{m}$.

\section{Gonadotropin regulation of Has gene expression in immature rat ovaries}

The expression levels of Has1 and Has2 genes in the ovaries of P21 rats treated with saline, $10 \mathrm{IU}$ eCG, or 10 IU hCG were examined. Both eCG and hCG acutely induced ovarian Has 1 gene expression within $3 \mathrm{~h}$, and the expression levels returned to basal levels $12 \mathrm{~h}$ after injection (Fig. 4A). On the other hand, only eCG but not hCG gradually induced Has2 gene expression from 3 to $48 \mathrm{~h}$ after treatment (Fig. 4B).

\section{Effects of 4-MU and DON on $\mathrm{HA}$ reduction and follicle growth in in vivo-treated rats and in vitro-cultured follicles}

The in vivo effects of two chemicals known to reduce HA synthesis and frequently used in the research on ovarian $\mathrm{HA}$ reduction were examined. In P21 rats, 2 days after saline injection, $\mathrm{HA}$ was abundantly detected in growing follicles (Fig. 5A), whereas treatments with $3.85 \mathrm{~g} / \mathrm{kg}$ body weight of $4-\mathrm{MU}$ or $5 \mathrm{mg} / \mathrm{kg}$ DON diminished ovarian HA synthesis and increased the number of atretic follicles (Fig. 5B and C and Table 1). In addition, the penetration of CD31-immunopositive endothelial cells into the granulosa cell layer was observed in $\sim 10 \%$ of total atretic follicles in the 4-MU-treated rats (Supplementary Figure 1, see section on supplementary data given at the end of this article).

To ascertain whether HA reduction induces the arrest of follicle growth and following follicular atresia more directly, we used an in vitro follicle culture system. Preantral follicles (100-140 $\mu \mathrm{m}$ in diameter) obtained from P14 rats progressed to grow in media containing $100 \mathrm{mIU} / \mathrm{ml}$ recombinant $\mathrm{FSH}$, whereas the addition of $10 \mathrm{TRU} / \mathrm{ml}$ Streptomyces HYAL to the media arrested follicle growth (Fig. 5D). The growth arrest was also observed on the addition of 4-MU at concentrations $>0.33 \mathrm{mM}$ (Fig. 5D).

\section{Discussion}

Most of the studies on ovarian HA have concentrated on the cumulus-oocyte complex of mature antral follicles during ovulation, but have scarcely examined growing preantral follicles. Indeed, cumulus expansion, HA accumulation associated with a dramatic morphological dynamism, is utilized as a marker of human oocyte maturation in assisted reproductive technology and is known to be required for normal in vivo ovulatory and subsequent fertilization processes in mammals and thus its concentration seems to be appropriate. On the other hand, glycosaminoglycans other than $\mathrm{HA}$ are known to be expressed in small growing follicles and play roles in folliculogenesis (Irving-Rodgers et al. 2010, Hatzirodos et al. 2012). HA accumulation in small preantral follicles of WT and Hyal1-null mice has recently been revealed 
A

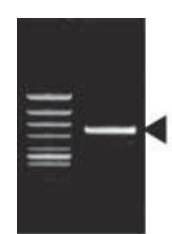

B

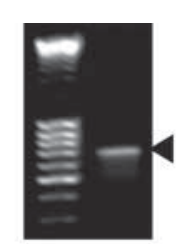

C

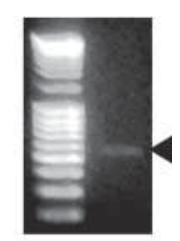

$\mathrm{D}$

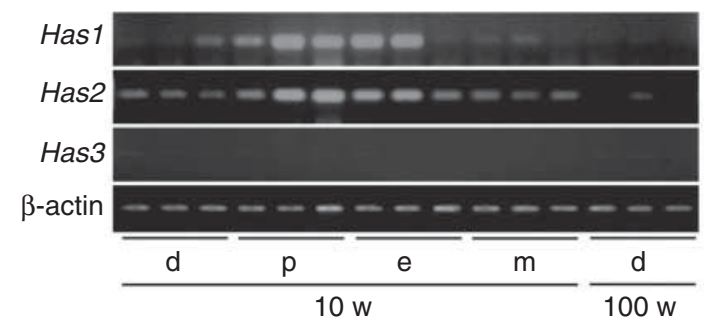

E

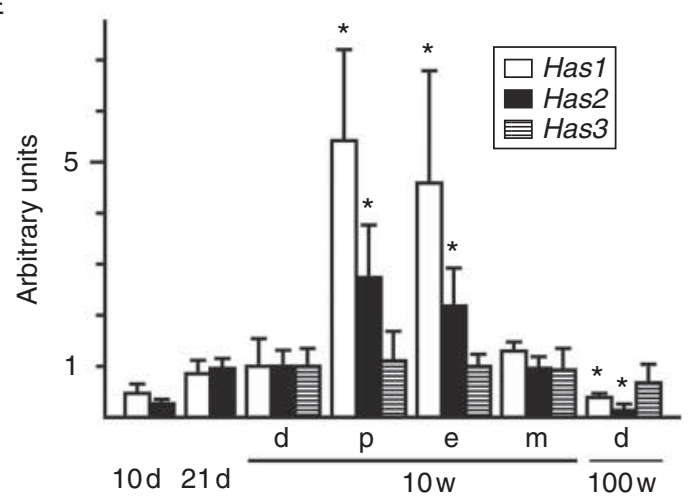

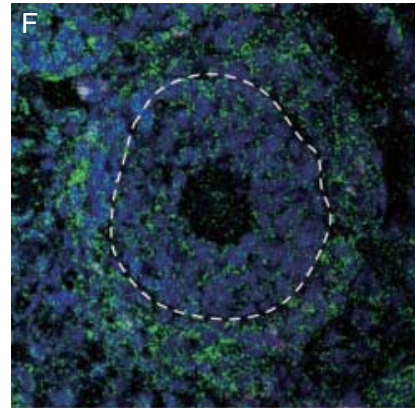
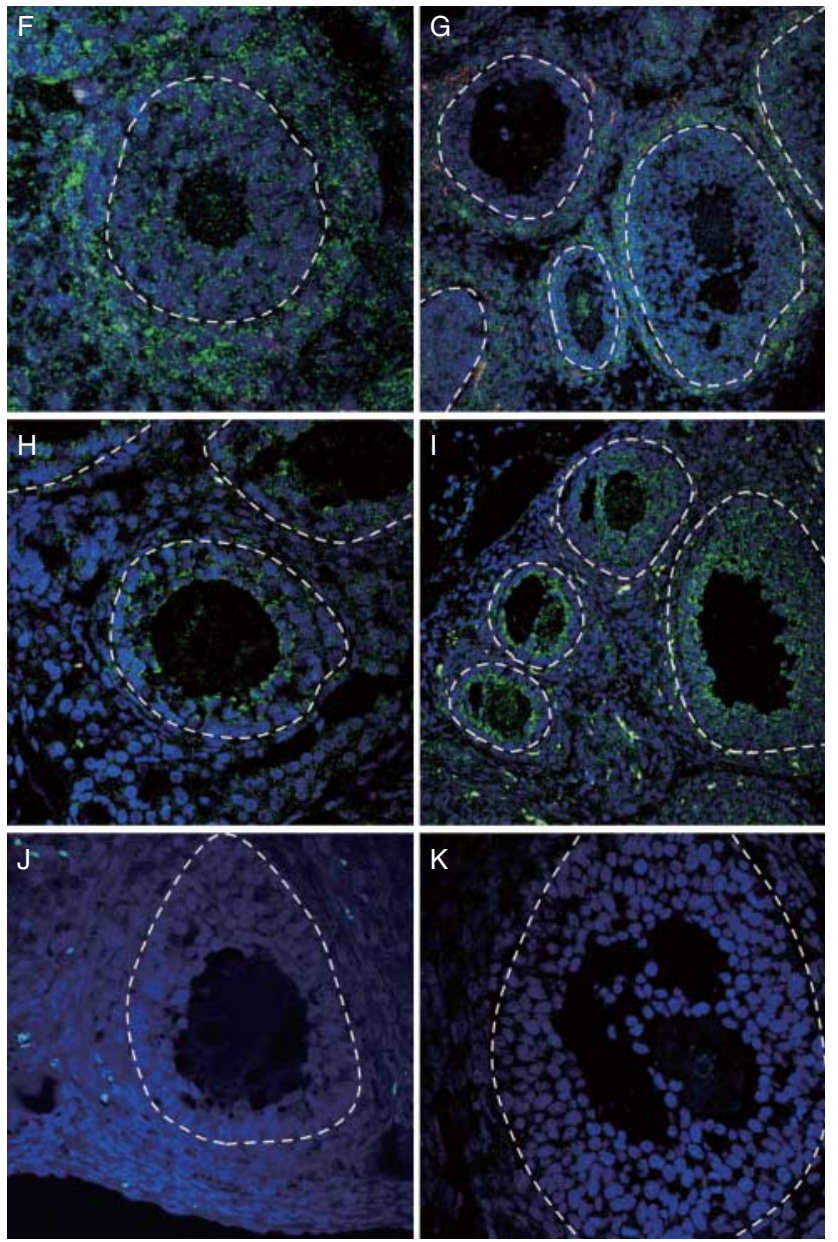

Figure 3 Gene expression of Has subtypes in rat ovaries. (A, B and C) Representative electrophoresis of RT-PCR products for Has genes in the ovaries of proestrus rats. Arrowheads indicate the positions of amplified PCR products for Has1 (A, 521 bp), Has2 (B, 692 bp), and Has3 (C, 537 bp). (D) Representative RT-PCR for Has1-3 and $\beta$-actin in the ovaries of 10-week-old cyclic and 100-week-old acyclic rats ( $n=3-6$ for each group). The estrous cycle consisting of diestrus, proestrus, estrus, and metestrus is indicated as d, p, e and m respectively. (E) Expression levels of $H$ as genes in the ovaries of perinatal, prepubertal, adult, and senescent rats. Values of the diestrus group from 10-week rats were adjusted to 1 . Asterisks indicate significant differences in values compared with those of the diestrus group (Dunn's multiple range test, $P<0.05)(\mathrm{F}, \mathrm{G}, \mathrm{H}$ and $\mathrm{I})$ Localization of the Has1 (F and G) and Has2 ( $\mathrm{H}$ and I) mRNAs in the preantral $(\mathrm{F}$ and $\mathrm{H})$ and antral (G and I) follicles of rat ovaries. Fluorescein-labeled antisense RNA probes for each gene were hybridized with ovarian sections followed by Hoechst 33258 staining. Dashed lines indicate the positions of follicular basal lamina. Autofluorescence of erythrocytes is visualized as red, yellow, or white. No signals were found when the sense sequence of Has 1 was used as a probe ( $\mathrm{J}$ and $\mathrm{K}$ ). Magnifications of objective: $\times 10$ for $\mathrm{G}$ and $\mathrm{I}$ and $\times 20$ for others.

for the first time (Dumaresq-Doiron et al. 2011), although its detailed localization and origin have not been determined. The expression of HA in small follicles has also been revealed using a biochemical technique (Irving-Rodgers et al. 2010). Furthermore, Orimoto et al. (2008) showed that Hyal1, Hyal2, and Hyal3 are expressed in the preantral/antral follicles of immature mice, which reflects the existence of $\mathrm{HA}$ in these follicles. In this study, we demonstrated that HA was localized in the ECM of granulosa and theca cell layers, including the basal lamina, of primary, preantral, and antral follicles of adult cycling ovaries and perinatal developing ovaries. Furthermore, the main site of ovarian HA accumulation shifted from the stromal region to the intrafollicular region at $\mathrm{P} 5$, when primary follicles are ontogenetically found. These new histological findings are necessary for further investigations on the involvement of $\mathrm{HA}$ production in follicle growth. High-molecular weight HA that accumulates in the ECM has antiangiogenic activity (West \& Kumar 1989, Itano 2008) and is found in joints, skin, and cornea (Kakehi et al. 2003), where too much disorderly vascularization is undesirable. The tunica adventitia of arteries is the main site of HA accumulation among blood vessels as well. On the other hand, the capillary vasculature begins to get detected from primary follicles, grows as the follicle grows, and remains on the outside of the follicular basal membrane until ovulation (Geva \& Jaffe 2004). Therefore, the transition of the main site of HA accumulation in the perifollicular region may reflect the 

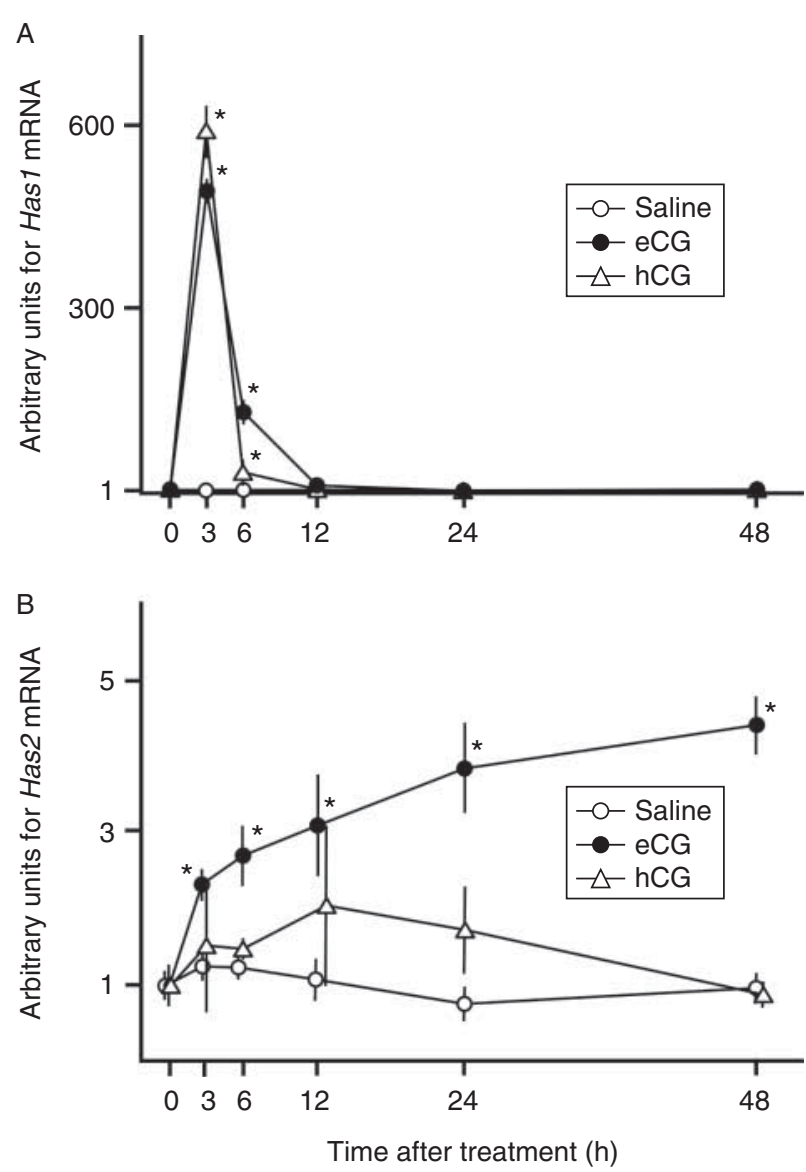

Figure 4 Effect of exogenous gonadotropins on the gene expression of Has1 and Has2 in immature rat ovaries. (A and B) P21 prepubertal rats ( $n=3-6$ for each group) were i.p. injected with saline (open circle), $10 \mathrm{IU}$ of eCG (closed circle), or $10 \mathrm{IU}$ of hCG (open rectangle) and the mRNA levels of Has1 (A) and Has2 (B) in ovaries were quantified 0, 3, $6,12,24$, and $48 \mathrm{~h}$ after injection. Data are indicated as means \pm S.E.M. Values of the control group at $0 \mathrm{~h}$ are expressed as 1 . Asterisks indicate significant differences in values compared with those of the saline-treated group at each time point (Dunn's multiple range test, $P<0.05$ ).

transition of roles in avascularity from the outermost layer of blood vessels to the basal lamina and granulosa cell layers of primary follicles. As the HA-rich tunica externa of arterial walls does not exist in newly vascularized capillaries, the transition would be required for perifollicular vasculogenesis.

As has been described above, the expression of each HAS isoform is spatially and temporally controlled (Itano 2008). In the ovaries of mammals, it has been revealed that all HAS isoforms are expressed at mRNA levels by RT-PCR and that HAS1 and HAS2 proteins are mainly localized in the theca and granulosa cell regions of mature antral follicles respectively (Richards 2005, Miyake et al. 2009). In this study, by carrying out in situ hybridization, for the first time, we demonstrated that the expression of Has1 and Has2 mRNAs occurs not only in antral follicles but also in small preantral follicles. We also demonstrated that the ovarian expression levels of these genes are upregulated at the periovulatory period, indicating that cyclic changes in some factors during the estrous cycle are involved in $\mathrm{HA}$ synthesis. In previous studies, it has been revealed that gonadotropin surge, which occurs at proestrus of the estrous cycle, triggers an increase in HA production via HAS2 induction in the cumulus cells of preovulatory follicles (Richards 2005), whereas the gonadotropin regulation of Has gene expression in small preantral follicles has not been examined. To clarify this, we used P21 immature rats and treated them with eCG and hCG as exogenous gonadotropins. The ovaries of prepubertal animals consist of fewer antral follicles but not mature preovulatory follicles and corpus luteum. eCG mainly mimics the action of FSH and weakly acts as a luteinizing hormone (LH), whereas hCG mimics the action of LH in mammals. In this study, we showed that the treatments of $\mathrm{P} 21$ rats with these gonadotropins modulated the expression levels of ovarian Has1 and Has2 genes; Has1 mRNA levels were acutely but transiently upregulated by both eCG and hCG treatments, whereas only eCG but not hCG continuously increased ovarian Has2 mRNA levels. These results indicated the gonadotropin regulation of Has1 and Has2 gene expression in immature growing follicles,
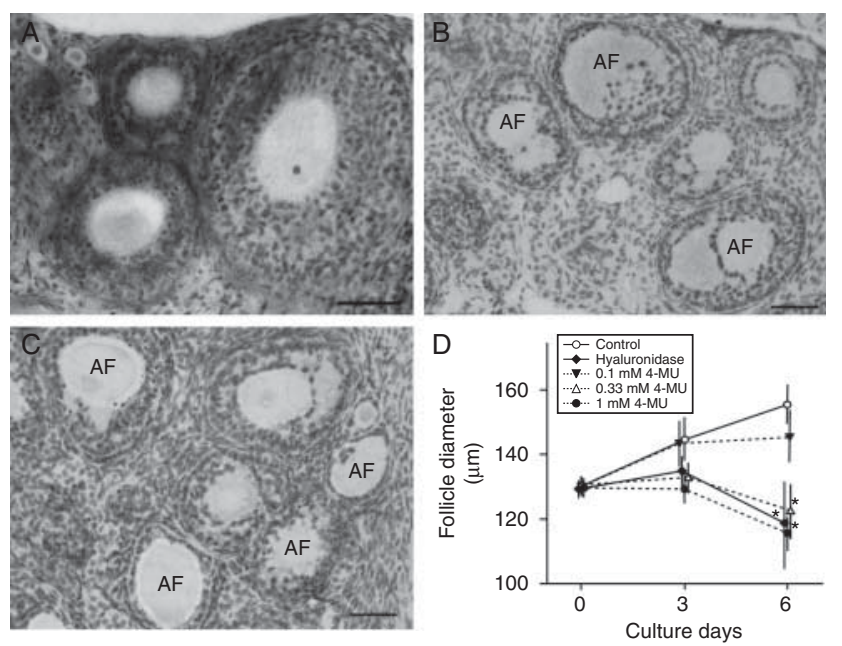

Figure 5 In vivo and in vitro effects of HA reduction on follicle growth. (A, B and C) Ovarian HA accumulation in P23 rats treated with saline (A), 4-MU (B), or DON (C) at P21. HA was detected in the healthy growing follicles of ovaries of control rats but scarcely in the ovaries of rats treated with $3.85 \mathrm{~g} / \mathrm{kg}$ body weight of 4-MU or with $5 \mathrm{mg} / \mathrm{kg}$ DON, in which many atretic follicles (AFs) were observed. Bars, $100 \mu \mathrm{m}$. $n=4-12$ for each treatment group. (D) In vitro effects of Streptomyces hyaluronidase or 4-MU treatments on follicular growth. Follicles collected from P14 rats (100-140 $\mu \mathrm{m}$ in diameter) were individually cultured with $0.1 \%$ DMSO (vehicle, open circle), $10 \mathrm{TRU} / \mathrm{ml}$ hyaluronidase (closed rhombus), or 4-MU (dashed lines) at final concentrations of $0.1 \mathrm{mM}$ (closed triangle), $0.33 \mathrm{mM}$ (open triangle), and $1 \mathrm{mM}$ (closed circle) ( $n=8-10$ for each treatment group) and the diameters of follicles were measured on days 0,3 , and 6 . Data are indicated as means \pm s.E.M. Asterisks indicate significant differences in values compared with those of the control group (Dunn's multiple range test, $P<0.05$ ). 
Table 1 In vivo effects of HA synthesis inhibitor 4-MU and gonadotropin treatments on follicular atresia. P21 immature rats were treated with saline, $10 \mathrm{IU}$ eCG, LD50 dose of 4-MU, or 4-MU + eCG. After a couple of days, ovaries were histologically examined. One ovary was obtained from each rat and total and atretic follicles in the primary and preantral secondary (class 3a-5b) and antral stage ( $\geq 6$ ) were counted as described previously (Takahashi et al. 2008). The data are given as means \pm S.E.M. with values rounded to the first decimal place.

\begin{tabular}{lcrrrr}
\hline & & \multicolumn{2}{c}{ Number of follicles per ovary } & & \\
\cline { 3 - 4 } Treatment & Class of follicle & \multicolumn{1}{c}{ Total } & Atretic & Ratio $^{\mathrm{a}}$ (\%) & $\boldsymbol{n}$ \\
\hline Saline & $3 \mathrm{a}-5 \mathrm{~b}$ & $92.5 \pm 8.3$ & $17.1 \pm 1.3$ & 18.5 & 12 \\
& $\geq 6$ & $0.2 \pm 0.0$ & $0.0 \pm 0.0$ & - & \\
eCG & $3 \mathrm{a}-5 \mathrm{~b}$ & $82.8 \pm 9.4$ & $8.4 \pm 1.2$ & 10.1 & 6 \\
& $\geq 6$ & $15.3 \pm 1.2$ & $1.4 \pm 0.0$ & 9.2 & \\
4-MU & $3 \mathrm{a}-5 \mathrm{~b}$ & $96.3 \pm 9.3$ & $88.0 \pm 5.1$ & $91.4^{\mathrm{b}}$ & 4 \\
& $\geq 6$ & $0.8 \pm 0.3$ & $0.8 \pm 0.3$ & $100^{\mathrm{b}}$ & \\
4-MU +eCG & $3 \mathrm{a}-5 \mathrm{~b}$ & $101.5 \pm 6.5$ & $90.5 \pm 6.5$ & $89.2^{\mathrm{b}}$ & 4 \\
& $\geq 6$ & $1.0 \pm 0.5$ & $1.0 \pm 0.5$ & $100^{\mathrm{b}}$ & \\
DON & $3 \mathrm{a}-5 \mathrm{~b}$ & $98.7 \pm 8.8$ & $90.0 \pm 8.3$ & $91.1^{\mathrm{b}}$ & 6 \\
& $\geq 6$ & $1.0 \pm 0.7$ & $1.0 \pm 0.7$ & $100^{\mathrm{b}}$ & \\
DON + eCG & $3 \mathrm{a}-5 \mathrm{~b}$ & $113.0 \pm 7.8$ & $93.0 \pm 7.5$ & $82.0^{\mathrm{b}}$ & 6 \\
& $\geq 6$ & $0.7 \pm 0.4$ & $0.7 \pm 0.4$ & $100^{\mathrm{b}}$ & \\
\hline
\end{tabular}

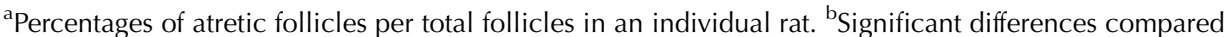
with the values of the saline- or eCG-treated groups at the $5 \%$ level (Dunn's multiple comparison test).

considering the main expression sites for these genes in the ovaries of $\mathrm{P} 21$ rats.

In this study, the 4-MU treatment inhibited follicle growth in vitro and induced ovarian $\mathrm{HA}$ reduction and follicular atresia in vivo. 4-MU is known to inhibit HA synthesis by depletion of UDP-glucuronic acid and downregulation of HAS activity (Kakizaki et al. 2004, Kultti et al. 2009). At doses used in the present study, 4-MU alleviates inflammatory responses caused by excess HA synthesis in the collagen-induced arthritis mouse model in vivo and in vitro (Yoshioka et al. 2013). We also observed that the glutamine analog DON, which inhibits glucosamine and consequent HA synthesis (Tempel et al. 2000), acted on ovaries in the same manner as in vivo 4-MU. Even when eCG was administered in combination with 4-MU or DON, HA production, normal follicle growth, and follicular avoidance of atresia were not observed. These two chemicals have been well known to reduce $\mathrm{HA}$ synthesis and have been frequently used for $\mathrm{HA}$ reduction studies in various cell lines and organs including ovary (Clark et al. 1987, Tempel et al. 2000, Kakizaki et al. 2004, Kultti et al. 2009, Tzuman et al. 2010, Yoshioka et al. 2013). On the other hand, these chemicals do not specifically exert effects on HASs, and therefore the relationship between follicular $\mathrm{HA}$ reduction and follicular atresia is still unclear. To clarify the relationship more directly, we examined the effect of Streptomyces HYAL, which specifically degrades HA but not other glycosaminoglycans such as chondroitin, chondroitin sulfate, dermatan sulfate, keratan sulfate, heparan sulfate, and heparin (Ohya \& Kaneko 1970), on the growth of in vitro-cultured preantral follicles and found that HYAL treatment inhibited follicle growth in culture under a condition of relatively high recombinant
FSH concentrations. This result indicates that HA reduction in follicular glycocalyx suppresses normal follicle growth and may consequently lead to follicular atresia. Additionally, decreased expression levels of Has 1 and Has2 mRNAs and follicular HA were observed in 100-week-old rats, suggesting that the reduction of HA synthesis potentially contributes to the fertility reduction observed in older animals.

The theca interna is the site of steroid hormone synthesis and follicular vasculature and therefore consists of steroid-producing endocrine cells, capillary endothelial cells, and fibroblasts. Just inside of the theca interna, the basal lamina defines follicle structure by itself and acts as a barrier between layers of extrafollicular theca cells and intrafollicular granulosa cells. Capillary intrusion into the granulosa cell layer occurs only in mature follicles in response to the gonadotropin surge during ovulation, but it does not occur in growing or atretic follicles (Geva \& Jaffe 2004). Although the fate of the thecal layer during atresia varies among species, a sharp reduction of perifollicular vascularity is commonly observed in mammals (Hsueh et al. 1994). Naturally, the intrusion does not occur during follicle growth, as is critical for the maintenance of follicular structure. In this study, we observed that HA synthesis was reduced in the ovaries of the 4-MU- and DON-treated rats and that CD31-immunopositive cells intruded into the granulosa cell layer of part of immature preantral follicles in the 4-MU-treated rats. As the accumulation of highmolecular weight HA in the ECM has antiangiogenic activity (West \& Kumar 1989, Spicer \& Tien 2004), vascular integrity around growing follicles may be impaired by HA reduction and the degraded follicular glycocalyx may permit endothelial cells to intrude. Indeed, Tempel et al. (2000) found the capillary intrusion 
into rat preovulatory follicles during DON treatment and, therefore, intrafollicular avascularity maintained by HA accumulation would exist in growing preantral follicles as well as preovulatory ones.

In this study, we confirmed HA to be present in the ECM of primary and more growing preantral and antral follicles, found Has1 and Has2 mRNAs to be localized in small growing follicles, and illustrated the transition of the main site of HA accumulation from the stromal region to follicular region at $\mathrm{P} 5$, all of which suggest the involvement of HA production in follicle growth. The gonadotropin regulation of Has gene expression in immature ovaries, which mainly contain small preantral follicles, was also revealed. HA reduction by Streptomyces HYAL caused the arrest of follicle growth in vitro, even under sufficient levels of gonadotropins for growth. Furthermore, both 4-MU and DON induced ovarian HA reduction and follicular atresia in vivo. Endothelial cells were detected in the granulosa cell layer of part of atretic follicles in rats treated with these chemicals. In conclusion, our results indicate that gonadotropin-regulated ovarian HA synthesis is involved in normal follicle growth.

\section{Supplementary data}

This is linked to the online version of the paper at http://dx.doi. org/10.1530/REP-13-0464.

\section{Declaration of interest}

The authors declare that there is no conflict of interest that could be perceived as prejudicing the impartiality of the research reported.

\section{Funding}

This work was supported in part by a grant-in-aid for scientific research from the Ministry of Education, Science, and Culture of the Japanese government to B Ishizuka (number 21592116). The funding source had no role in the study.

\section{Author contribution statement}

$\mathrm{N}$ Takahashi contributed to the study concept and design; the acquisition, analysis, and interpretation of data; and the drafting of this manuscript. W Tarumi provided technical support for the study, especially for in vitro follicle culture. B Ishizuka managed the funding and supervised the study. All authors critically reviewed the manuscript for intellectual content.

\section{Acknowledgements}

The authors thank Ms Naomi Hamada for her technical and administrative assistance. The corresponding author named a daughter Matrix after this work.

\section{References}

Camenisch TD, Spicer AP, Brehm-Gibson T, Biesterfeldt J, Augustine ML, Calabro A Jr, Kubalak S, Klewer SE \& McDonald JA 2000 Disruption of hyaluronan synthase-2 abrogates normal cardiac morphogenesis and hyaluronan-mediated transformation of epithelium to mesenchyme. Journal of Clinical Investigation 106 349-360. (doi:10. 1172/JCl10272)

Clark CC, Richards CF, Pacifici M \& Iozzo RV 1987 The effects of 6-diazo-5oxo-L-norleucine, a glutamine analogue, on the structure of the major cartilage proteoglycan synthesized by cultured chondrocytes. Journal of Biological Chemistry 262 10229-10238.

Dumaresq-Doiron K, Edjekouane L, Orimoto AM, Yoffou PH, Gushulak L, Triggs-Raine B \& Carmona E 2011 Hyal-1 but not Hyal-3 deficiency has an impact on ovarian folliculogenesis and female fertility by altering the follistatin/activin/smad3 pathway and the apoptotic process. Journal of Cellular Physiology 227 1911-1922. (doi:10.1002/jcp.22919)

Fries E \& Kaczmarczyk A 2003 Inter-alpha-inhibitor, hyaluronan and inflammation. Acta Biochimica Polonica 50 735-742.

Genasetti A, Vigetti D, Viola M, Karousou E, Moretto P, Rizzi M, Bartolini B, Clerici M, Pallotti F, De Luca G et al. 2008 Hyaluronan and human endothelial cell behavior. Connective Tissue Research $\mathbf{4 9}$ 120-123. (doi:10.1080/03008200802148462)

Geva E \& Jaffe RB 2004 Ovarian angiogenesis. In The Ovary, pp 305-317. Eds PCK Leung\& EY Adashi. Amsterdam: Elsevier Academic Press.

Hatzirodos N, Nigro J, Irving-Rodgers HF, Vashi AV, Hummitzsch K, Caterson B, Sullivan TR \& Rodgers RJ 2012 Glycomic analyses of ovarian follicles during development and atresia. Matrix Biology 31 45-56. (doi:10.1016/j.matbio.2011.10.002)

Hsueh AJ, Billig H \& Tsafriri A 1994 Ovarian follicle atresia: a hormonally controlled apoptotic process. Endocrine Reviews 15 707-724. (doi:10. 1210/er.15.6.707)

Irving-Rodgers HF \& Rodgers RJ 2005 Extracellular matrix in ovarian follicular development and disease. Cell and Tissue Research 322 89-98. (doi:10.1007/s00441-005-0042-y)

Irving-Rodgers HF, Hummitzsch K, Murdiyarso LS, Bonner WM, Sado Y, Ninomiya Y, Couchman JR, Sorokin LM \& Rodgers RJ 2010 Dynamics of extracellular matrix in ovarian follicles and corpora lutea of mice. Cell and Tissue Research 339 613-624. (doi:10.1007/s00441-009-0905-8)

Itano N 2008 Simple primary structure, complex turnover regulation and multiple roles of hyaluronan. Journal of Biochemistry 144 131-137. (doi:10.1093/jb/mvn046)

Kakehi K, Kinoshita M \& Yasueda S 2003 Hyaluronic acid: separation and biological implications. Journal of Chromatography. B, Analytical Technologies in the Biomedical and Life Sciences 797 347-355. (doi:10.1016/S1570-0232(03)00479-3)

Kakizaki I, Kojima K, Takagaki K, Endo M, Kannagi R, Ito M, Maruo Y, Sato H, Yasuda T, Mita S et al. 2004 A novel mechanism for the inhibition of hyaluronan biosynthesis by 4-methylumbelliferone. Journal of Biological Chemistry 279 33281-33289. (doi:10.1074/jbc. M405918200)

Kultti A, Pasonen-Seppanen S, Jauhiainen M, Rilla KJ, Karna R, Pyoria E, Tammi RH \& Tammi MI 2009 4-Methylumbelliferone inhibits hyaluronan synthesis by depletion of cellular UDP-glucuronic acid and downregulation of hyaluronan synthase 2 and 3. Experimental Cell Research 315 1914-1923. (doi:10.1016/j.yexcr.2009.03.002)

Laurent C, Hellstrom S, Engstrom-Laurent A, Wells AF \& Bergh A 1995 Localization and quantity of hyaluronan in urogenital organs of male and female rats. Cell and Tissue Research 279 241-248. (doi:10.1007/ BF00318480)

Lennon FE \& Singleton PA 2011 Hyaluronan regulation of vascular integrity. American Journal of Cardiovascular Disease 1 200-213.

Miyake $Y$, Sakurai M, Tanaka S, Tunjung WA, Yokoo M, Matsumoto $H$, Aso H, Yamaguchi T \& Sato E 2009 Expression of hyaluronan synthase 1 and distribution of hyaluronan during follicular atresia in pig ovaries. Biology of Reproduction 80 249-257. (doi:10.1095/biolreprod.108. 067694)

Ochsner SA, Russell DL, Day AJ, Breyer RM \& Richards JS 2003 Decreased expression of tumor necrosis factor- $\alpha$-stimulated gene 6 in cumulus cells of the cyclooxygenase-2 and EP2 null mice. Endocrinology 144 1008-1019. (doi:10.1210/en.2002-220435) 
Ohya T \& Kaneko Y 1970 Novel hyaluronidase from streptomyces. Biochimica et Biophysica Acta 198 607-609. (doi:10.1016/00052744(70)90139-7)

Orimoto AM, Dumaresq-Doiron K, Jiang JY, Tanphaichitr N, Tsang BK \& Carmona E 2008 Mammalian hyaluronidase induces ovarian granulosa cell apoptosis and is involved in follicular atresia. Endocrinology 149 5835-5847. (doi:10.1210/en.2008-0175)

Pedersen T \& Peters H 1968 Proposal for a classification of oocytes and follicles in the mouse ovary. Journal of Reproduction and Fertility 17 555-557. (doi:10.1530/jrf.0.0170555)

Richards JS 2005 Ovulation: new factors that prepare the oocyte for fertilization. Molecular and Cellular Endocrinology 234 75-79. (doi:10.1016/j.mce.2005.01.004)

Romero S \& Smitz J 2009 Epiregulin can effectively mature isolated cumulus-oocyte complexes, but fails as a substitute for the hCG/epidermal growth factor stimulus on cultured follicles. Reproduction 137 997-1005. (doi:10.1530/REP-08-0523)

Salustri A, Camaioni A, Di Giacomo M, Fulop C \& Hascall VC 1999 Hyaluronan and proteoglycans in ovarian follicles. Human Reproduction Update 5 293-301. (doi:10.1093/humupd/5.4.293)

Spicer AP \& Tien JY 2004 Hyaluronan and morphogenesis. Birth Defects Research. Part C, Embryo Today: Reviews 72 89-108. (doi:10.1002/bdrc. 20006)

Takahashi N, Itoh MT \& Ishizuka B 2008 Human chorionic gonadotropin induces nestin expression in endothelial cells of the ovary via vascular endothelial growth factor signaling. Endocrinology 149 253-260. (doi:10.1210/en.2007-0774)
Tarumi W, Tsukamoto S, Okutsu Y, Takahashi N, Horiuchi T, Itoh MT \& Ishizuka B 2012 Androstenedione induces abnormalities in morphology and function of developing oocytes, which impairs oocyte meiotic competence. Fertility and Sterility 97 469-476. (doi:10.1016/j.fertnstert. 2011.11.040)

Tempel C, Gilead A \& Neeman M 2000 Hyaluronic acid as an anti-angiogenic shield in the preovulatory rat follicle. Biology of Reproduction 63 134-140. (doi:10.1095/biolreprod63.1.134)

Tzuman YC, Sapoznik S, Granot D, Nevo N \& Neeman M 2010 Peritoneal adhesion and angiogenesis in ovarian carcinoma are inversely regulated by hyaluronan: the role of gonadotropins. Neoplasia 12 51-60.

West DC \& Kumar S 1989 Hyaluronan and angiogenesis. Ciba Foundation Symposium 143 187-201 (discussion 201-207, 281-285).

Yoshioka Y, Kozawa E, Urakawa H, Arai E, Futamura N, Zhuo L, Kimata K, Ishiguro N \& Nishida Y 2013 Suppression of hyaluronan synthesis alleviates inflammatory response in murine arthritis and in human rheumatoid synovial fibroblasts. Arthritis and Rheumatism 65 1160-1170.

Received 19 September 2013

First decision 14 October 2013

Revised manuscript received 5 November 2013

Accepted 11 November 2013 